\title{
The Application of Economic Value Added on Green Facilities of Urban Agriculture
}

\author{
Kuo Wei $\mathrm{Hsu}^{1}$ and Shang Zhen Liao ${ }^{2}$ \\ ${ }^{1}$ Professor, Urban Planning, Land Development, Chaoyang University of Technology,No.168, Jifeng E. Rd., Wufeng Dist., Taichung \\ City 413, Taiwan (R.O.C.) \\ ${ }^{2}$ Urban Planning, Land Development, Chaoyang University of Technology, No.168, Jifeng E. Rd., Wufeng Dist., Taichung City 413, \\ Taiwan (R.O.C.)
}

\begin{abstract}
Green facilities of urban agriculture offer a fertile ground for green innovation, such as rooftop gardens, green curtains, and indoor plant growing, which create a new forms of urban farming economy. The previous studies for cost-benefit analysis of urban agriculture indicated that green facilities could contribute both quantitative and qualitative benefits. The value of green facility strategies of urban agriculture may often be underestimated without transforming qualitative benefits to quantitative benefits. This study examined the effects of green facilities of urban agriculture development in Taiwan. The market reaction was explored by adopting economic value added (EVA) technique for the measurement of both quantitative and qualitative value contributed by green facilities. The results from this study support that there exists interaction between qualitative factors such as indirect economic benefits and social psychological benefits and quantitative factors, agricultural production and energy saving impacted by green facilities. The study concluded that consumers of urban agricultural crops are willing to pay more for ecofriendly products. The establishment of relationship between urban agricultural production and consumption can contribute to sustainability while generating economic opportunities.
\end{abstract}

Keywords. Green Facilities, Urban Agriculture, Economic Value Added (EVA)

\section{Introduction}

Urban agriculture integrated with green facilities has been widely accepted in major metropolitan cities of the world. Urban agriculture offers not only agricultural products but also a platform for green innovation by linking its technology to the principles of sustainable urban environment. Green facilities of urban agriculture offer a fertile ground for green innovation, such as rooftop gardens, green curtains, and indoor plant growing, which create a new forms of urban farming economy. In recent years, Taiwan's public sector and non-profit organization have been pushing forward the urban agriculture policy and act. However, the previous studies for cost-benefit analysis of urban agriculture that had ignored transforming qualitative benefits to willingness to pay leaded to underestimate the influences of green facilities. Thus except rewarding green facilities of urban agriculture, to expose the real benefits can encourage private sector to participate the urban agriculture act. The objectives of this study were:

- To explore the interaction between qualitative and quantitative value-creation factors of green facilities of urban agriculture.
- To apply economic value added (EVA) technique on exploring the determining costs and benefits of urban agriculture associated with green facilities.

\section{Literature Review}

The urban expansion and the change in people's working style or habits led many young people choose to work in urban area in the recent years. However, the reduction of the population who cultivate and the traditional agricultural land' s usage amount led the culture of traditional agriculture disappear gradually. Agriculture has emerged in cities at that time. Urban agriculture develops different forms of urban agriculture with different urban issues and social backgrounds. It complies with the four conditions, purpose, space area, planting scale, and production technology to constitute the definition of urban agriculture. [1] The obvious performance of agricultural production and management is highly intensive mode of operation, and it achieve the production, processing and marketing of integrated management, and thus achieve a high degree of agricultural development and urban services for the special features. Most of the crops that are cultivated are 
crops of relatively high economic value with short production cycles. Most of the crops are sold to local residents or sold to nearby restaurants through selfproduction and sales, using local markets for sale. Urban agriculture can offer benefits as follows: 1 . source of fresh and safe products, 2. opportunity for urban residents' engagement in agricultural activities, 3. open space for disaster management, 4. resource for recreation and well-being, and 5. education and awareness-raising for improving urban residents' understanding of agriculture and food issues. Urban agriculture can contribute to sustainability and well-being in cities by

\section{Taiwan's Green Facilities of Urban Agriculture Experience}

The most common green facilities of urban agriculture are planting plants on the roof and public open space with fruits, vegetables, and herbs. The type of facilities in urban agriculture in the neighborhood can build a more complete industrial structure. [3] Green facilities of urban agriculture achieved the green, leisure and production of

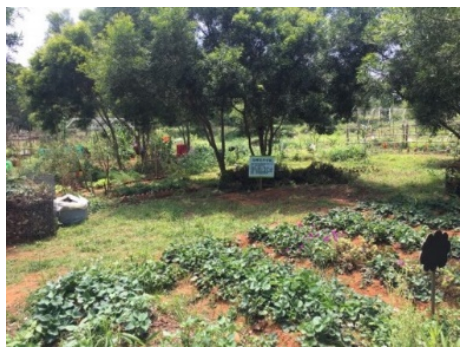

Figure 1. flat agriculture

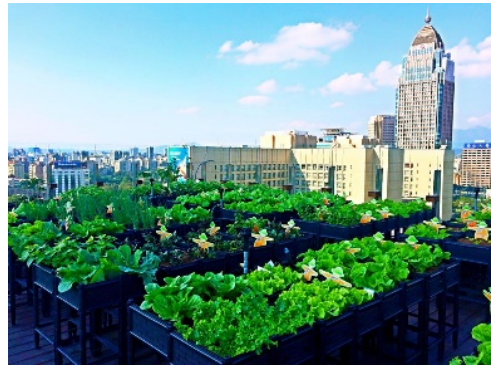

Figure 2. roof agriculture

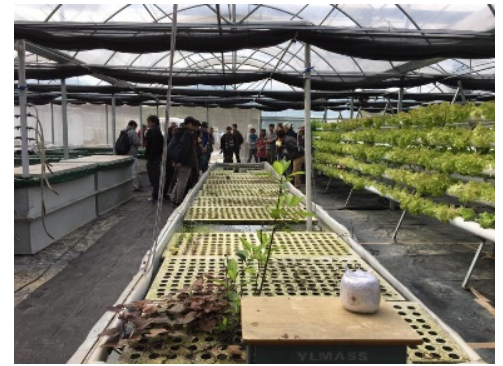

Figure 3. vertical agriculture
Most public sector building roof has green facilities. However, the popularization rate of urban agriculture in Taiwan is still not significantly improved. The main reason is that the public cannot apply the concept of economic added value on green facilities of urban agriculture lead to ineffective result for private sectors in increasing the area of permeable surface for storm water management, or reducing the heat-island effect by cooling the air. Through green meeting places in neighbourhoods, group-based nature activities (e.g. walking or willow pollarding) and gardening (shared gardens for the elderly and allotment gardens)[2] ,urban agriculture also can contribute to biodiversity and ecosystem services by providing habitats and managing species. Furthermore, it can reduce food miles and even provide bio-energy resources.

multiple functions. Building plants on the roof also provides many ecological and economic benefits. [4] Green roofs have a layer of living plants on top of the structure and the waterproofing elements. Green roofs can be installed on a wide range of buildings, from industrial facilities to private residences. Figure 1 to 3 presented the typical types of urban agriculture in Taiwan.

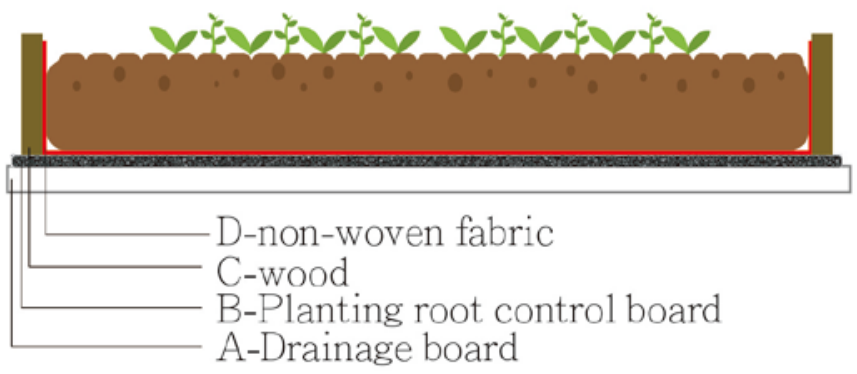

Figure 4. Common mold materials

In order to encourage the public to use the unused space in community for farming, Taichung City government has been promoting "City Food Forest" act since 2016 to increase food security and contribute to the greening of the city as well as raise awareness of the potential of
Taiwan. Recently, the reduction of green facilities costs created opportunities for private sectors to participate the act due to setting materials innovation. The setting of green facilities materials of urban agriculture are composed of drainage board, planting root control board, wood, and non-woven fabric shown in Figure 4. sustainability projects among citizens. "City Food Forest" act successfully implemented several cases in elementary schools those not only produced crops but also achieved the educational goals as shown in Figure 5-7. 


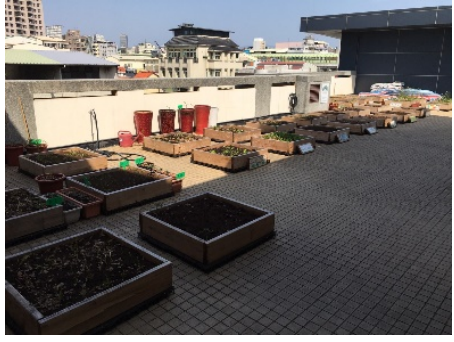

Figure 5. Huilai elementary school demonstration

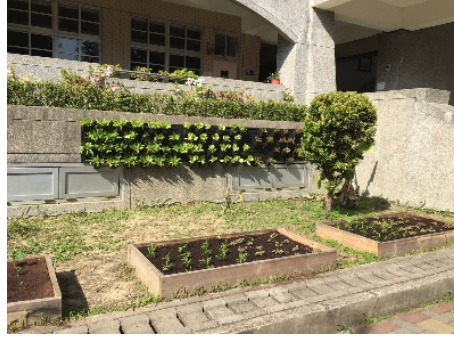

Figure 6. Four-plows elementary school demonstration

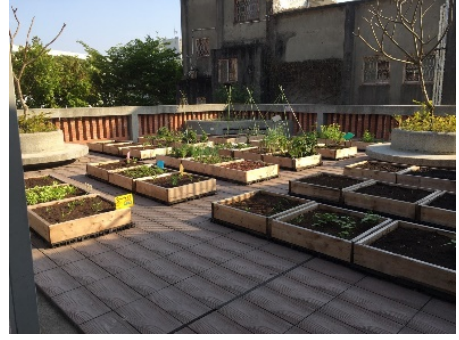

Figure7. Quiaoxiao elementary school demonstration

\section{Method}

Economic value added is a financial performance metric based on residual wealth, calculated by deducting a firm's cost of capital from operating profit. In essence, it is the value generated from funds invested in a business. EVA asserts that businesses should create returns during a certain period at a rate above their cost of capital. This study explored the net operating profits of both quantitative and qualitative benefits. EVA presents the following formula for its calculation:

The formula for EVA.

EVA $=$ NOPAT $-($ Capital Invested $\mathrm{x}$ WACC $)$

Where NOPAT $=$ Net Operating Profits After Tax
Capital invested $=$ Equity + long-term debt at the beginning of the period

WACC $=$ Weighted Average Cost of Capital

The study identified costs for green facilities of urban agriculture for individual producer that reflected the costs that project participants incur in producing food. The setting costs of green facilities on urban agriculture included 4 parts: 1 .operating costs: land rent and labour, 2. tillage apparatus: wooden boxes, planting pots, support frame, 3. cultivation medium: soil, and 4. composting facilities: kitchen compost bin, as shown in table 1.

Table 1. Setting costs of green facilities

\begin{tabular}{lll}
\hline Categories & Items & Net Price \\
\hline Operating costs & Land rent & No additional cost \\
& Labour & No additional cost \\
\hline \multirow{2}{*}{ Tillage apparatus } & Wooden boxes & NT\$3,000/m2 \\
& Planting pots & NT\$720 / m2 \\
& Support frame & NT\$560 / m2 \\
\hline Cultivation medium & Soil & NT\$1,250 / m2 \\
\hline Composting facilities & Kitchen compost Bin & NT\$300 / pcs
\end{tabular}

\section{Conclusion}

\subsection{Urban Agriculture Benefits}

The study reviewed the extant literatures and organized two quantitative factors, agricultural production and energy saving and two qualitative factors, indirect economic benefits and social and psychological benefits for the economic value added of green facilities on urban agriculture. Urban Farms may be limited by the city's design, so it may not have the formal using right of land.
However, Urban Farms can plan to reuse the Green-roof to achieve the facilities green and reach its EAV. For example, this model can also be used to review the benefits of urban agriculture construction and review the probabilities of sustainable development. This study explored the practical cases to verify the interaction between qualitative and quantitative factors of green facilities contribute to urban agriculture summarized in figure 8 . 


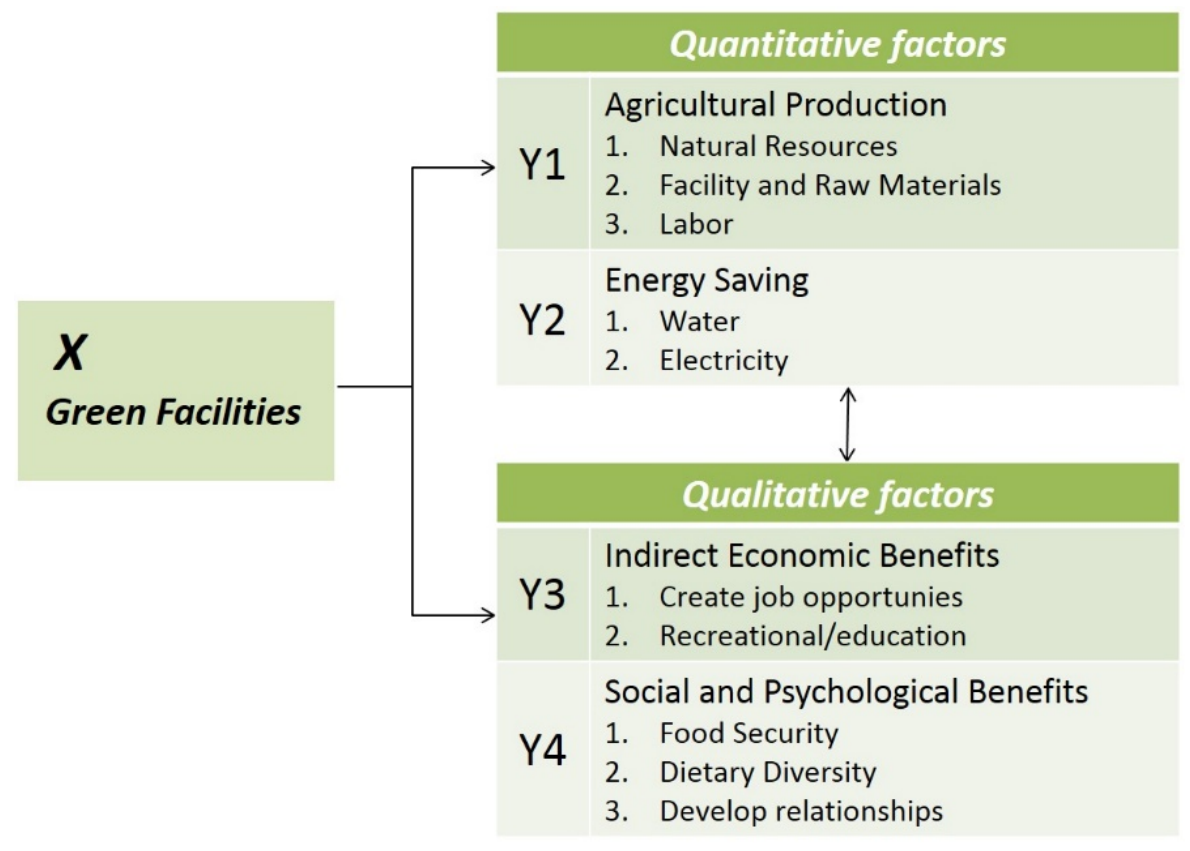

Figure 8. Interaction between qualitative factors and quantitative factors of urban agriculture impacted by green facilities.

Y1 to Y3 and Y4: Labor is one of the major costs of agricultural production. Green facilities farming might create social relationship and job opportunities.

Y3 to Y2: Green facilities of urban agriculture can provide urban farmers the training about business management, technical skills and marketing which might increase the agricultural production or save the energy by rainwater recovery system, and roof green energy.

Y4 to Y3: Urban agriculture is a marketing concept of local production and consumption which can directly identify food security and offer food nutrition and safety education.

\subsection{Discussions}

The most important issue for public sector when promoting green facilities of urban agriculture is not the roof planting technology but the communication with citizen for its costs and benefits. The study employed EVA to indicate the interaction between qualitative and quantitative factors that effectively offer the communication platform between public and private sectors that promoted the green technology application for urban agriculture development.

\section{References}

1. Hodgson, K. \& Campbell, M.C. \& Bailey, M. (2011). Urban Agriculture: Growing Healthy, Sustainable Places.

2. Health Council of the Netherlands and Dutch Advisory Council for research on Spatial Planning (2004). Nature and health. The influence of nature on social, psychological and physical well-being.

3. Qiu Yinghao. (2015). Urban Agriculture Creates New Vision of Pastoral City.

4. Kristin L. Getter \&D. Bradley Rowe. (2006). The Role of Extensive Green Roofs in Sustainable Development. 